\title{
ANALISIS PERTUMBUHAN KAWASAN PENGEMBANGAN EKONOMI TERPADU (KAPET) BIAK DI PROVINSI PAPUA
}

\author{
Growth analysis of integrated economic development zone (KAPET) \\ Biak in Papua Province
}

\section{Johanis A. Msiren ${ }^{1}$}

Diterima: 13 Juli 2015 Disetujui: 2 Februari 2016

\begin{abstract}
Abstrak: Penelitian ini bertujuan untuk menganalisis tipologi wilayah, sektor unggulan dan potensi sumberdaya ikan sedangkan analisis yang digunakan adalah Tipologi Klassen, LQ/SSA/Overlay dan Tangkapan Maksimum Lestari (MSY). Hasil penelitian ini mendeskripsikan bahwa Kapet Biak dari aspek pertumbuhan ekonomi dan pendapataan per kapita diklasifikasikan menjadi wilayah yang belum berkembang sedangkan indikator IPM dan pertumbuhan ekonomi klasifikasinya terjadi lompatan drastis menjadi wilayah yang cepat maju dan cepat tumbuh kecuali kabupaten Waropen.Kabupaten yang memiliki sektor unggulan adalah Waropen dan Supiori yaitu sektor pertanian, industri, bangunan dan jasa sedangkan Nabire, Kepulauan Yapen dan Biak Numfor memiliki sektor yang kompetitif dan komparatif. Pengembangan wilayah berbasis sektor unggulan lokal sehingga setiap kabupaten di Kapet Biak wajib mengembangkan potensi sektor lokalnya yang didukung oleh sumberdaya lahan di setiap Kabupaten tersebut. Potensi daya dukung lahan untuk sektor pertanian terluas di Kabupaten Nabire dan terkecil di Kabupaten Supiori.Selain sumberdaya yang telah dan akan dikelola oleh setiap wilayah di Kapet Biak terdapat pula sumberdaya bersama yang masih belum dikelola secara terintegrasi dan terpadu. Sumberdaya bersama (CPRs) tersebut adalah laut, CPRs memiliki potensi sumberdaya ikan yang potensi lestarinya fluktuatif dan dapat diandalkan untuk meningkatkan pertumbuhan ekonomi dan pendapatan per kapita di setiap wilayah Kapet Biak.
\end{abstract}

Kata kunci: kapet biak, pertumbuhan ekonomi, sektor unggulan dantangkapan maksimum lestari

\begin{abstract}
The purpose of this study was to analyze the typology of the region, leading sectors and the potential of fish resources, tools of analized was Typology Klassen, LQ/SSA/Overlay and Maximum Sustainable Yield (MSY). Results of this studied describes that Kapet Biak from the aspect of economic growth and income per capita classified into emerging regions but human development index (HDI)indicators and economic growth occur jumped to fast growth and development regions except Waropen. Waropen and Supiori had leading sectors those are agriculture, industry, construction and services, while Nabire, Yapen and Biak Islands Numfor only had competitive and comparative sectors. Regional development based on potential of local leading sector should be every regional in Kapet Biak to develop local potention it's supported by land carrying capacity in every regional in Kapet Biak. Land carrying capacity for agriculture sector widest in Nabire regency and the smallest in Supiori. Beside resources have been and will develop by every regency in Kapet Biak, there are also common pool resources (CPRs) had not yet development integration. CPRs it's sea, it had fish resources potention and fluctuative maximum sustainable yield but it's a leading potention to growth economic and increase income per capita in every region on Kapet Biak.
\end{abstract}

Key words: kapet biak, economic growth, leading sector, maximum sustainable yield.

1 Institut Pertanian Bogor

Korespondensi: johnmsiren@yahoo.com 


\section{Pendahuluan}

Kawasan pengembangan ekonomi terpadu (KAPET) merupakan upaya pemerintah dalam meningkatkan pertumbuhan ekonomi di tiga belas wilayah Indonesia. Salah satunya di Provinsi Papua, yang dikenal dengan nama KAPET Biak, dipayungi oleh keppres No. 90 tahun 1996 yang terus mengalami revisi hingga terbitnya keppres No. 150 Tahun 2000. Definisi Kapet adalah suatu wilayah geografis dengan batas-batas tertentu yang mempunyai syarat antara lain (a) memiliki potensi untuk cepat tumbuh dan atau; (b) mempunyai sektor unggulan yang dapat menggerakkan pertumbuhan ekonoi di wilayah sekitarnya dan atau; (c) memiliki potensi pengembalian investasi yang besar. Kapet Biak menerapkan pola nodal yaitu terdiri dari inti (Biak Numfor) dan beberapa hinterland (Supiori, Kepulauan Yapen, Waropen dan Nabire), dengan pendekatan pembangunan ekonomi sebagai indikator. Hal ini dipertegas oleh Rostow yang menyatakan bahwa hakekat pembangunan secara sederhana adalah terjadinya pertumbuhan ekonomi (Rustiadi, Saefulhakim, \& Panuju, 2011). Secara kelembagaan pemerintah telah membentuk badan pengelola Kapet Biak yang bertugas memberi rekomendasi teknis kepada pemerintah daerah yang berkaitan dengan investasi, penyederhanaan perijinan dan peraturan melalui pelayanan satu atap, pelayanan data dan informasi bagi investor, serta pengembangan konsep ekonomi terpadu. Lembaga ini telah menetapkan beberapa sektor yang dapat memacu pertumbuhan perekonomian di kawasan tersebut antara lain pariwisata, pertanian dan perindustrian, namun sektor-sektor ini kurang memberikan dampak terhadap pertumbuhan perekonomian di kawasan tersebut, catatan BPS melaporkan bahwa sektor yang memberikan kontribusi tertinggi di wilayah Kapet Biak adalah sektor bangunan dan jasa (Badan Pusat Statistik Provinsi Papua, 2013).Tanpa adanya infrastruktur pendukung yang memadai dan kualitas sumberdaya manusia yang rendah, maka sulit terjadi pertumbuhan ekonomi di kawasan ini. Selain itu sumberdaya bersama yang dimiliki Kapet Biak adalah laut. Sumberdaya ini memiliki potensi pelagis besar, pelagis kecil, demersal dan biota laut lainnya sehingga dapat dikelola untuk pengembangan wilayah. Tujuan umum dari penelitian ini adalah mendeskripsikan pertumbuhan Kapet Biak dalam kurung waktu lima belas tahun dan tujuan spesifiknya ialah menganalisis tipologi wilayah, menganalisis sektor unggulan dan menganalisis potensi sumberdaya ikan.

\section{Hasil danPembahasan}

\section{Klasifikasi Wilayah}

Klassen mengelompokkan wilayah berdasarkan indikator laju pertumbuhan ekonomi dan pendapatan per kapita. Adapun laju pertumbuhan ekonomi dan pendapatan per kapita di wilayah Kapet Biak tahun 2006 hingga 2012, tersaji pada Gambar 1.

Gambar 1 menjelaskan bahwa pertumbuhan ekonomi di wilayah Kapet Biak dalam kurung waktu tujuh tahun tampak ada perbedaan antara kelima Kabupaten di kawasan tersebut, rerata Kabupaten yang tertinggi pertumbuhan ekonominya adalah Kabupaten Waropen $(12,76 \%)$ dan yang terendah pertumbuhan ekonominya adalah Kabupaten Kepulauan Yapen $(5,54 \%)$. Selanjutnya indikator pendapatan per kapita yang merujuk pada PDRB ADHK 2000, tahun 2006 - 20012. Pendapatan per kapita di wilayah Kapet Biak disajikan pada Gambar 2.

Informasi yang tersaji pada Gambar 2, mengindikasikan bahwa rerata pendapatan per kapita tertinggi di Kabupaten Supiori sebesar Rp. 8,21 juta/tahun dan terendah di Kabupaten Kepulauan Yapen senilai Rp. 4,31 juta/tahun, penyebab tinggi dan rendahnya pertumbuhan ekonomi dan pendapatan per kapita di Kabupaten tersebut karena dipengaruhi oleh sektor jasa, pertanian dan juga komitmen stakeholders dalam 
mengembangkan wilayahnya sesuai visi dan misi kepala daerah yang telah ditetapkan, sebuah gejala yang terjadi apabila setiap lima tahun terjadi restrukturisasi pimpinan daerah maka yang terjadi adalah perubahan visi dan misi sehingga memulai dengan babak baru dalam suatu program pembangunan di wilayah Kapet Biak akibatnya tidak terjadi pertumbuhan dan perkembangan wilayah tersebut.

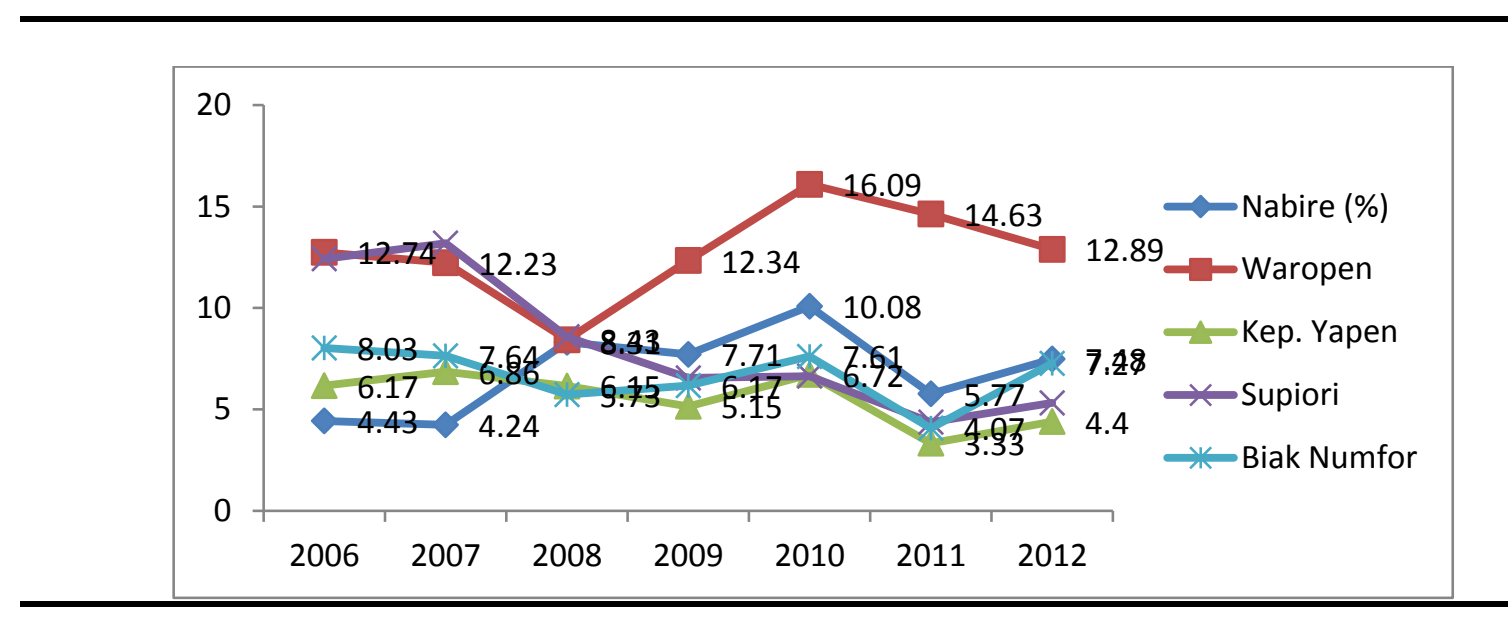

Gambar 1. Laju Pertumbuhan Ekonomi di Wilayah Kapet Biak

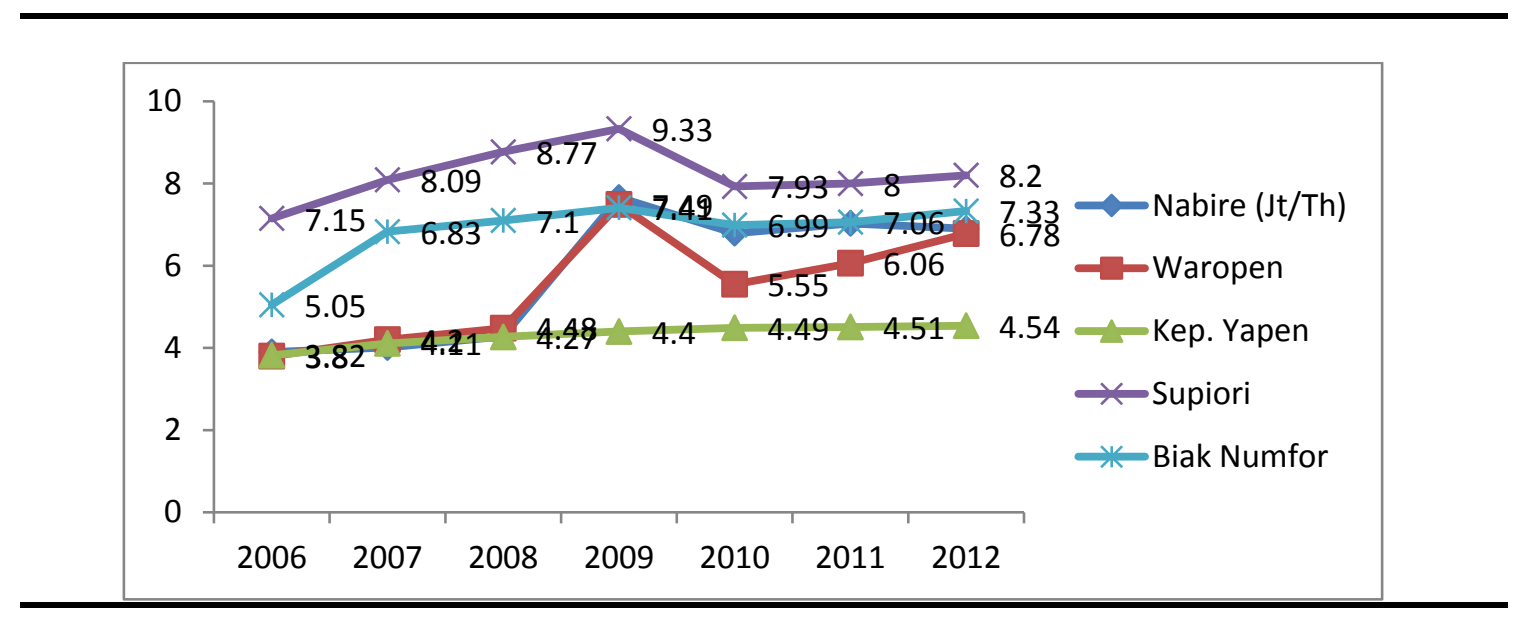

Gambar 2. Pendapatan Per Kapitadi Wilayah Kapet Biak

Sedangkan pertumbuhan ekonomi dan pendapatan per kapita di Provinsi Papua, tertera pada Gambar 3. Gambar 3 mendeskrispsikan bahwa rerata pertumbuhan ekonomi di Provinsi Papua selama tahun 2006 - 2012 sebesar 0,17\% sedangkan pendapatan per kapita senilai Rp. 8,96 juta/tahun, merujuk pada data yang tersaji pada Gambar 3, 4 dan Gambar 5, maka di lakukan komparasi rerata pertumbuhan ekonomi dan pendapatan per kapita antara wilayah kapet Biak dengan Provinsi Papua, hasil komparasinya terlihat pada Tabel 1. 


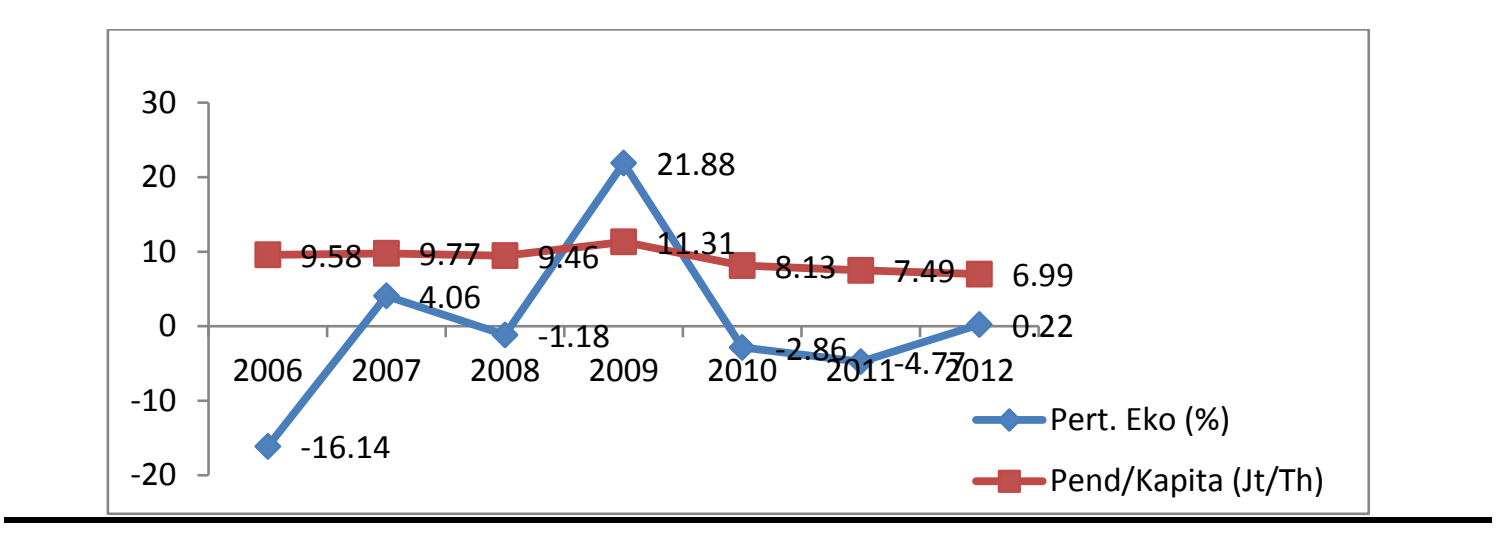

Gambar 3. Pertumbuhan Ekonomi danPendapatan Per Kapita di Provinsi Papua

Tabel 1. Tipologi Wilayah Menurut Klassen

\begin{tabular}{|l|l|l|}
\hline & \multicolumn{1}{|c|}{ yi $\begin{array}{r}\text { Pendapatan }(8,98) \\
\text { (jt/th) }\end{array}$} & \\
Pertumbuhan Ekonomi (\%) & & \\
\hline ri $>\mathrm{r}(0,17)$ & Nabire $(5,79)$ & W \\
$(6,86)$ & Waropen $(5,47)$ & Wilayah Maju \\
$(12,76)$ & Kep. Yapen $(4,31)$ & \\
$(5,54)$ & Supiori $(8,21)$ & \\
$(8,15)$ & Biak Numfor $(6,83)$ & \\
$(6,65)$ & Wilayah Tidak Berkembang & Wilayah Sedang Berkembang \\
\hline ri $<\mathrm{r}$ & & \\
& & \\
\hline
\end{tabular}

Tabel 1 mendeskripsikan bahwa wilayah Kapet Biak masuk dalam kuadran III atau diklasifikasikan menjadi wilayah yang belum berkembang, sebagaimana diketahui bahwa klasifikasi wilayah terdiri dari empat klasifikasi yaitu : (1) wilayah yang relatif tertinggal atau wilayah yang tidak berkembang, diindikasikan oleh pertumbuhan ekonomi dan pendapatan per kapita lebih rendah dari pembandingnya yang lebih besar (Provinsi Papua); (2) wilayah yang belum berkembang, dicirikan oleh pertumbuhan ekonomi lebih besar dari pendapatan per kapita; (3) wilayah tertekan atau wilayah sedang berkembang, indikatornya pendapatan per kapita lebih besar dari pertumbuhan ekonomi dengan wilayah pembangding; dan (4) wilayah maju atau berkembang pesat, ditandai oleh pertumbuhan ekonomi dan pendapatan per kapita lebih besar dari wilayah pembandingnya. Tingginya pendapatan per kapita di provinsi Papua karena dipengaruhi oleh sektor pertambangan dan sektor jasa tetapi memiliki pertumbuhan ekonomi yang sangat rendah dikarenakan keterbatasan sumberdaya manusia dan tingginya tingkat kemiskinan. Sumber pertumbuhan ekonomi tidak lagi dipengaruhi oleh melimpahya sumberdaya alam, banyak tenaga kerja dan kemajuan teknologi tetapi paling dipengaruhi oleh fakor sumberdaya manusia (Bing, 2011).

Merujuk pada pernyataan diatas maka indikator lain penentu pertumbuhan dan perkembangan suatu wilayah adalah Indeks Pembangunan Manusia (Human Development Index). UNDP sejak 1990 menggunakan IPM yang merupakan indikator komposit tunggal yang walaupun tidak dapat mengukur semua dimensi pembangunan manusia, tetapi mengukur tiga dimensi pokok pembangunan manusia yang dinilai mencerminkan status kemampuan dasar (basic capabilities) penduduk. Ketiga kemampuan dasar itu adalah (1) tingkat kesehatan yang tercermin dengan umur panjang dan sehat yang mengukur 
peluang hidup, (2) berpengetahuan dan berketrampilan, serta (3) akses terhadap sumberdaya yang dibutuhkan untuk mencapai standar hidup layak. (Rustiadi et al, 2011).

Indeks Pembangunan Manusia dan persentase kemiskinan di wilayah Kapet Biak, tersaji pada Tabel 2. Merujuk pada Tabel 24, rerata IPM tertinggi di wilayah Kapet Biak adalah di Kabupaten Biak Numfor sedangkan yang terendah di Kabupaten Waropen, begitu pula untuk persentase kemiskinan tertinggi di Kabupaten Supiori dan terkecil di Kabupaten Biak Numfor. Adapun Indeks Pembangunan Manusia di Provinsi Papua, tersaji pada Gambar 4.

Tabel 2. Indeks Pembangunan Manusia di Wilayah Kapet Biak

\begin{tabular}{lccccccc}
\hline Wilayah & \multicolumn{7}{c}{ Indeks Pembangunan Manusia/Tahun } \\
\cline { 2 - 8 } Kapet Biak & 2006 & 2007 & 2008 & 2009 & 2010 & 2011 & 2012 \\
\hline Nabire & 65,19 & 65,60 & 66,10 & 66,54 & 66,81 & 67,33 & 68,03 \\
Waropen & 61,60 & 61,97 & 62,46 & 62,85 & 63,27 & 63,71 & 64,24 \\
Kep. Yapen & 67,00 & 68,06 & 68,68 & 69,13 & 69,69 & 70,19 & 70,98 \\
Supiori & 66,23 & 66,92 & 67,55 & 68,06 & 68,46 & 68,92 & 69,19 \\
Biak Numfor & 67,25 & 68,55 & 68,99 & 69,35 & 69,95 & 70,33 & 70,68 \\
\hline
\end{tabular}

Sumber : BPS Provinsi Papua.

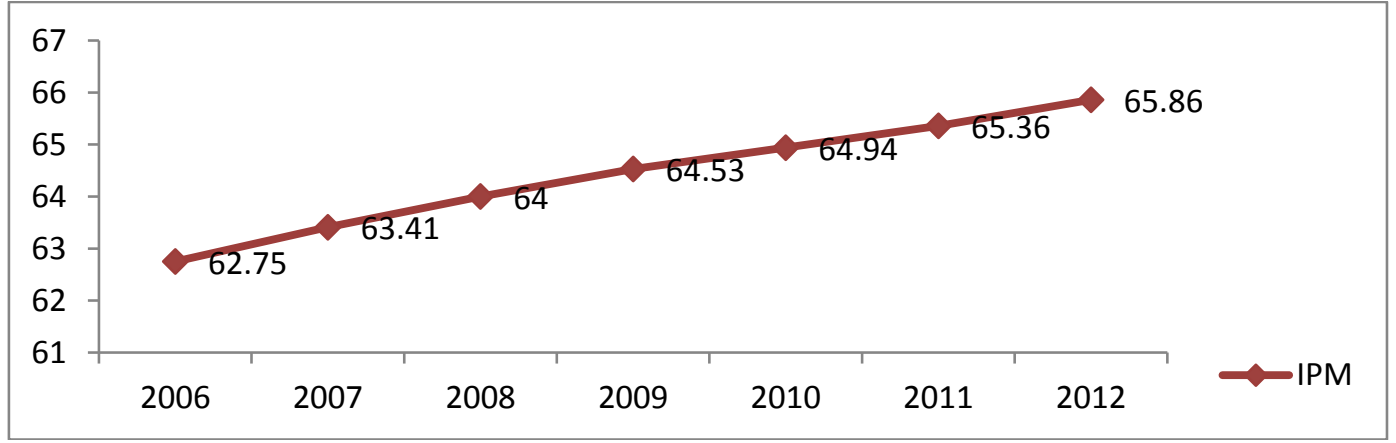

Sumber : BPS Provinsi Papua

\section{Gambar 4. Indeks Pembangunan Manusia di Provinsi Papua}

Klasifikasi wilayah tidak hanya mengacu pada indikator pertumbuhan ekonomi dan pendapat per kapita tetapi dapat dikelompokkan berdasarkan Indeks Pembangunan Manusia dan Pertumbuhan Ekonomi. Tipologi daerah pada dasarnya membagi daerah berdasarkan dua indikator utama, yaitu IPM dan pertumbuhan ekonomi daerah. Dengan menentukan rata-rata IPM sebagai sumbu vertikal dan rata-rata pertumbuhan ekonomi daerah sebagai sumbu horizontal (Kuncoro, 2004). Pengelompokan wilayah menurut IPM dan pertumbuhan ekonomi di wilayah Kapet Biak tersaji pada Tabel 3.

Tabel 3. Tipologi Wilayah Kapet Biak

\begin{tabular}{|l|l|l|}
\hline & & \multicolumn{1}{|c|}{ yi $<$ y $>y(64,41)$} \\
Pertumbuhan Ekonomi & & \multicolumn{1}{|c|}{} \\
\hline ri $>\mathrm{r}(0,17)$ & (III) & (I) \\
$(6,86)$ & Waropen $(62,87)$ & Nabire $(66,51)$ \\
$(12,76)$ & & Kep. Yapen $(69,10)$ \\
$(5,54)$ & & Supiori $(68,87)$ \\
$(8,15)$ & & Biak Numfor $(69,30)$ \\
$(6,65)$ & & (II) \\
\hline ri $<\mathrm{r}$ & (IV) & \\
\hline
\end{tabular}


Tabel , menggambarkan bahwa wilayah Kapet Biak adalah wilayah yang maju dan cepat tumbuh kecuali Kabupaten Waropen merupakan wilayah yang belum berkembangan karena nilai Indeks Pembangunan Manusia di Kabupaten Waropen lebih kecil dari Provinsi Papua.

\section{Sektor Unggulan}

Pengembangan wilayah tanpa memperhatikan keunggulan potensi daerah, skala prioritas dan komiten bersama maka suatu wilayah tidak memiliki arah dan tujuan yang jelas dalam mensejahterakan masyarakatnya. Oleh karena itu sektor unggulan menjadi penggerak utama (prime mover) yang harus diimplementasikan dalam pengembangan suatu wilayah, penentuan sektor unggulan di kawasan ini melalui analisis $L Q, S S A$ dan Daya Dukung Lahan.

a) Hasil Analisis $L Q$ di Wilayah Kapet Biak

Tabel 4. Hasil Analisis LQ di Wilayah Kapet Biak

\begin{tabular}{|c|c|c|c|c|c|c|c|c|c|}
\hline $\begin{array}{l}\text { Wilayah } \\
\text { Kapet Biak }\end{array}$ & 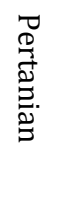 & 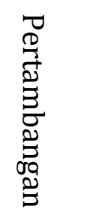 & 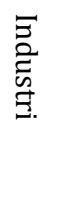 & 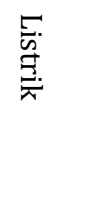 & 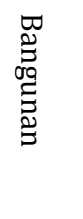 & 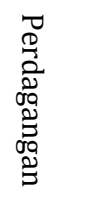 & 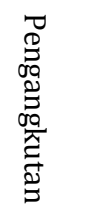 & 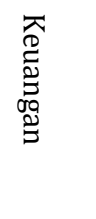 & $\overrightarrow{\stackrel{\mathscr{N}}{0}}$ \\
\hline Nabire & 1,50 & 2,32 & 0,24 & 0,52 & 0,97 & 0,85 & 0,54 & 0,57 & 0,71 \\
\hline Waropen & 1,75 & 0,20 & 0,15 & 0,28 & 1,20 & 0,46 & 0,34 & 0,44 & 1,61 \\
\hline Kep.Yapen & 0,71 & 0,18 & 0,37 & 0,70 & 1,12 & 0,97 & 0,68 & 1,41 & 1,79 \\
\hline Supiori & 1,01 & 0,26 & 1,01 & 0,03 & 1,15 & 1,72 & 0,94 & 0,77 & 0,71 \\
\hline Biak Numfor & 0,49 & 0,21 & 2,21 & 1,86 & 0,93 & 1,18 & 1,74 & 1,38 & 0,89 \\
\hline
\end{tabular}

Tabel 4. Mendeskripsikan bahwa terdapat beberapa sektor basis yang sama antar beberapa kabupaten yaitu sektor pertanian, industri, bangunan, perdagangan, keuangan dan jasa tetapi terdapat pula perbedaan sektor basis yaitu sektor pertambangan, listrik dan pengangkutan. Kabupaten Nabire dan Waropen dibatasi oleh daratan pada satu wilayah sehingga cenderung memiliki karakteristik wilayah yang hampir seragam. Sektor pertanian kabupaten Nabire dipengaruhi oleh melimpahnya produksi jeruk siam dengan luas komoditas ini sebesar 511.241,21 Ha dengan produksi sebanyak 14.000 ton/tahun (Badan Pusat Statistik Kabupaten Nabire, 2013), sedangkan Waropen lebih di pengaruhi oleh sub sektor pertanian tanaman pangan dan kehutanan bergitupula Supiori. Sektor pertambangan hanya di dominasi oleh kabupaten Nabire fakta ini didukung oleh potensi tambang emas, nikel dan uranium yang dimilikinya, sektor industri lebih dominan di Kabupaten Biak Numfor dikarenakan kondisi topografi yang relatif datar dan bebatuan sehingga wilayah lebih ideal sebagai wilayah industri, terdapat perusahaan seperti PT. Wapoga Mutiara Industri yang mengelola kayu, CV Garuda Mas yang memproduksi kopi bubuk garuda dan beberapa home industry yang mengelola antara lain pengolahan tahu/tempe, abon ikan, kue/roti, meubel, minyak kelapa rakyat, pengolahan ikan asap dan ikan asin, begitupula sektor listrik mempunyai jumlah pelanggan terbanyak rumah tangga sebanyak 17.509 pelanggan, komersial 2.160 pelanggan dan industri 7 pelanggan (BPS Provinsi Papua, 2013), sedangkan sektor bangunan berkembang pesat di Kabupaten Waropen, Kepulauan Yapen dan Supiori karena giat melakukan pembangunan infrastruktur guna sebagai sarana penunjang di kabupaten tersebut. Sektor perdagangan di dominasi Kabupaten Biak Numfor dan Supiori karena kedua wilayah ini saling 
bertetangga sehingga terjadi transaksi komoditas primer, sekunder dan tersier antar pedagang sehingga memicu peningkatan PDRB. Sektor transportasi di ungguli oleh Kabupaten Biak Numfor baik transportasi darat, laut dan udara karena banyak aparat pemerintah yang berdomisili di Kabupaten Biak Numfor lalu bekerja di Kabupaten Supiori, selain itu terdapat bandar udara berskala internasional dan beberapa pelabuhan beton yang selalu dilabuhi kapal besar dan kecil. Sektor jasa khususnya sub sektor administrasi pemerintah dan pertahanan di dominasi oeh Kabupaten Waropen dan Kepulauan Yapen, mengindikasikan bahwa subsidi dana pusat terhadap kedua kabupaten ini lebih besar jika dikomparasi dengan Nabire, Supiori dan Biak Numfor.

b). Hasil Analisis Shift Share

Tabel 5. Hasil Analisis Shift Share di Wilayah Kapet Biak

\begin{tabular}{|c|c|c|c|c|c|c|c|c|c|}
\hline $\begin{array}{l}\text { Wilayah } \\
\text { Kapet } \\
\text { Biak }\end{array}$ & 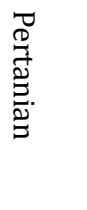 & 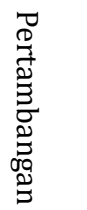 & 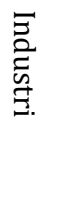 & 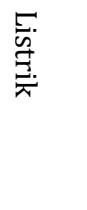 & 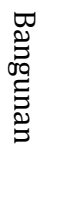 & 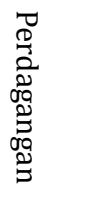 & 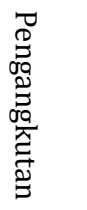 & 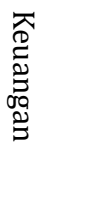 & 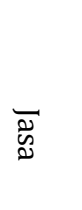 \\
\hline Nabire & $-0,03$ & $-0,02$ & 0,55 & 0,00 & 0,16 & 0,28 & 0,20 & 1,43 & $-0,02$ \\
\hline Waropen & 0,04 & 0,23 & 0,18 & $-0,06$ & 0,65 & $-0,04$ & 0,00 & 1,15 & 0,91 \\
\hline Kep.Yapen & 0,02 & $-0,05$ & 0,24 & 0,15 & $-0,20$ & $-0,02$ & $-0,05$ & $-0,07$ & $-0,08$ \\
\hline Supiori & 0,09 & 0,28 & 0,03 & 0,46 & $-0,11$ & $-0,15$ & $-0,20$ & 0,01 & 0,18 \\
\hline Biak Numfor & 0,33 & 0,24 & $-0,02$ & $-0,02$ & $-0,13$ & $-0,07$ & $-0,04$ & $-0,36$ & $-0,11$ \\
\hline
\end{tabular}

Merujuk pada Tabel 5 menggambarkan bahwa sektor yang kompetitif dikembangkan pada wilayah Kapet Biak ditandai oleh nilai positif. Sektor ini telah memiliki nilai tambah dan daya saing dari aspek kualitas, kuantitas dan kontinuitas.

c). Potensi Kemampuan Lahan

Data aktual yang tersaji pada Tabel 4 dan 5 dipadukan dengan potensi kemampuan lahan agar dapat mendukung pengembangan sektor pertanian. Secara spasial kelas kemampuan lahan di wilayah Kapet Biak tertera pada Gambar 5.

Gambar 5, memberikan informasi bahwa kelas kemampuan lahan di wilayah Kapet Biak terdiri dari enam kelas kemampuan lahan yang luas dan faktor penghambatnya masingmasing, terlihat pada Tabel 6.

Tabel 6. Kelas Kemampuan Lahan di Wilayah Kapet Biak

\begin{tabular}{crr}
\hline Kelas Kemampuan Lahan & Luas (Ha) & Persentase (\%) \\
\hline I & $2.386,21$ & 0,10 \\
IId2 & $108.766,12$ & 4,61 \\
IIi1 & 692,33 & 0,03 \\
II t4 & $301.423,17$ & 12,78 \\
IIId3 & 25,35 & 0,00 \\
IIIi2 & $83.998,38$ & 3,56 \\
IIIt4 & $66.315,11$ & 2,81 \\
IVd4 & 520,62 & 0,02 \\
IVi3 & $71.887,42$ & 3,05 \\
VIi4 & $293.270,17$ & 12,43 \\
VIk3 & $6.355,79$ & 0,27 \\
VIII6 & $1.253 .708,59$ & 53,15 \\
VIIIt5 & $156.519,53$ & 6,64 \\
\hline
\end{tabular}

Sumber : Hasil Analisis 


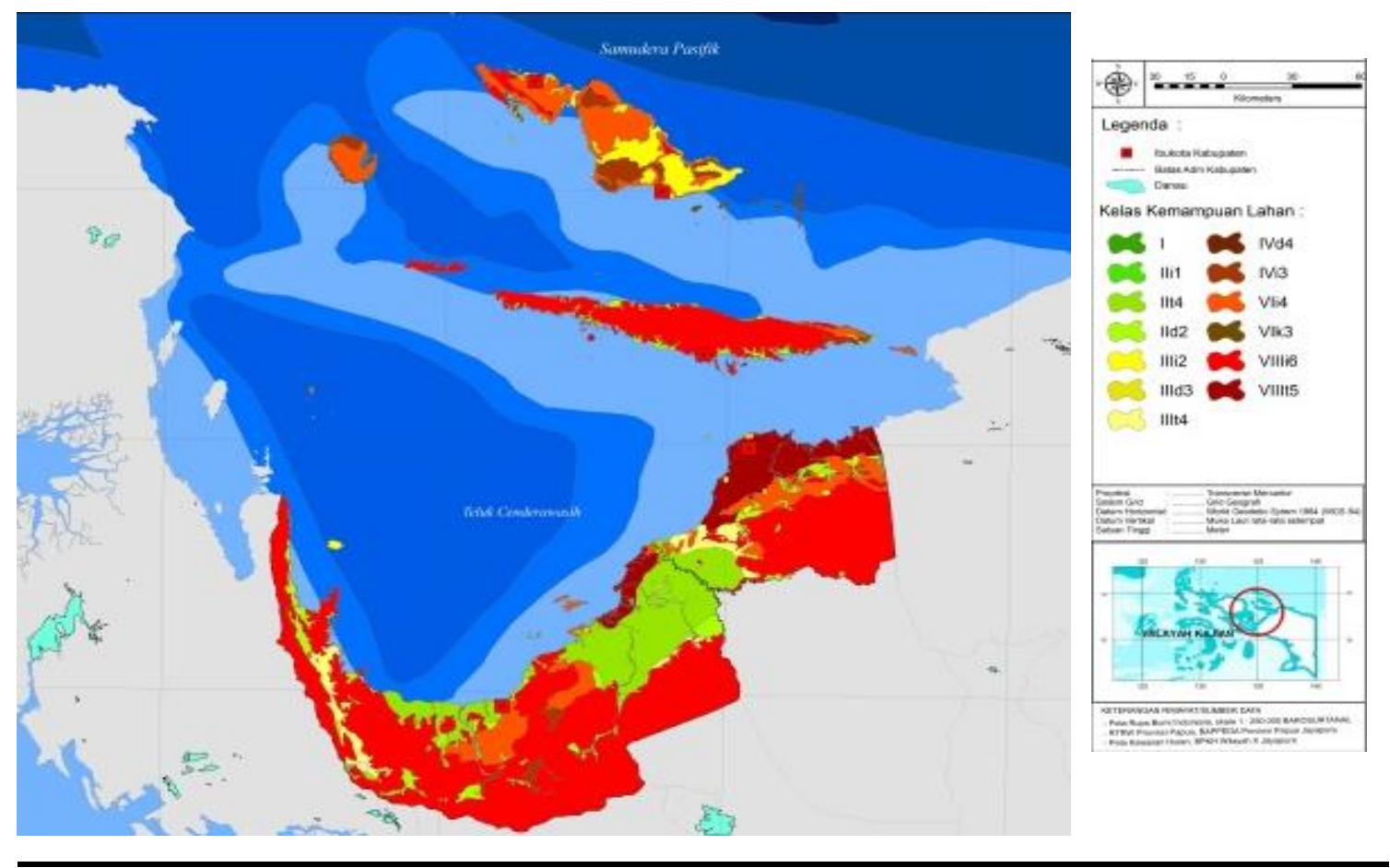

Gambar 5. Peta Kelas Kemampuan Lahandi wilayah Kapet Biak

Tabel 7. Potensi Sektor Unggulan di Wilayah Kapet Biak

\begin{tabular}{|c|c|c|c|c|}
\hline $\begin{array}{l}\text { Wilayah Kapet } \\
\text { Biak }\end{array}$ & $\begin{array}{l}\text { Bukan Sektor } \\
\text { Unggulan } \\
(S S A-\text { dan } L Q<1)\end{array}$ & $\begin{array}{l}\text { Sektor Kompetitif } \\
(S S A+\text { dan } L Q<1)\end{array}$ & $\begin{array}{l}\text { Sektor Basis } \\
(S S A-\text { dan } L Q>1)\end{array}$ & $\begin{array}{l}\text { Sektor Unggulan } \\
(S S A+\text { dan } L Q>1)\end{array}$ \\
\hline Nabire & $\begin{array}{l}\text { Listrik } \\
\text { Jasa }\end{array}$ & $\begin{array}{l}\text { Industri } \\
\text { Bangunan } \\
\text { Perdagangan } \\
\text { Pengangkutan } \\
\text { Keuangan }\end{array}$ & $\begin{array}{l}\text { Pertanian } \\
\text { Pertambangan }\end{array}$ & $\begin{array}{l}\text { Pelagis Kecil } \\
\text { Pelagis Besar } \\
\text { Demersal }\end{array}$ \\
\hline Waropen & $\begin{array}{l}\text { Listrik } \\
\text { Perdagangan } \\
\text { Pengangkutan }\end{array}$ & $\begin{array}{l}\text { Pertambangan } \\
\text { Industri } \\
\text { Keuangan }\end{array}$ & & $\begin{array}{l}\text { Pertanian } \\
\text { Bangunan } \\
\text { Jasa } \\
\text { Udang } \\
\text { Pelagis Kecil } \\
\text { Pelagis Besar } \\
\text { Demersal }\end{array}$ \\
\hline Kep. Yapen & $\begin{array}{l}\text { Pertambangan } \\
\text { Perdagangan } \\
\text { Pengangkutan }\end{array}$ & $\begin{array}{l}\text { Pertanian } \\
\text { Industri } \\
\text { Listrik }\end{array}$ & $\begin{array}{l}\text { Bangunan } \\
\text { Keuangan } \\
\text { Jasa }\end{array}$ & $\begin{array}{l}\text { Demersal } \\
\text { Pelagis Kecil } \\
\text { Pelagis Besar }\end{array}$ \\
\hline Supiori & Pengangkutan & $\begin{array}{l}\text { Pertambangan } \\
\text { Listrik } \\
\text { Keuangan } \\
\text { Jasa }\end{array}$ & $\begin{array}{l}\text { Bangunan } \\
\text { Perdagangan }\end{array}$ & $\begin{array}{l}\text { Pertanian } \\
\text { Industri } \\
\text { Demersal } \\
\text { Pelagis Kecil } \\
\text { Pelagis Besar }\end{array}$ \\
\hline Biak Numfor & $\begin{array}{l}\text { Bangunan } \\
\text { Jasa }\end{array}$ & $\begin{array}{l}\text { Pertanian } \\
\text { Pertambangan }\end{array}$ & $\begin{array}{l}\text { Industri } \\
\text { Listrik } \\
\text { Perdagangan } \\
\text { Pengangkutan } \\
\text { Keuangan }\end{array}$ & $\begin{array}{l}\text { Demersal } \\
\text { Pelagis Besar } \\
\text { Pelagis Kecil }\end{array}$ \\
\hline
\end{tabular}


Secara agregat lahan yang dapat dikelola untuk mendukung sektor pertanian di wilayah Kapet Biak adalah lahan kelas I, II, III dan IV sehingga luas lahan yang dapat dimanfaatkan sebesar 636.014,73 hektar, sedangkan lahan kelas V hingga VIII lebih diarahkan sebagai kawasan konservasi. Hal ini ditegaskan oleh pernyataan yang menyatakan bahwa lahan kelas I sampai IV merupakan lahan yang sesuai untuk usaha pertanian, sedangkan kelas V sampai VIII tidak sesuai untuk usaha pertanian atau diperlukan biaya yang sangat tinggi untuk pengelolaannya, sedangkan faktor pembatas lahan terdiri faktor drainase (d), lereng (i), tekstur (t), dan kedalaman sampai kerikil/padas/plinthit (k) (Hardjowigeno \& Widiatmaka, 2011). Selanjutnya untuk memperoleh potensi sektor unggulan dilakukan perpaduan antara nilai $L Q>1$ dan nilai SSA yang bernilai positif. Kompilasi kedua indikator ini tersaji pada Tabel 7.

Tabel 10 mendeskripsikan bahwa secara agregat sektor bangunan dan jasa memiliki potensi sebagai sektor unggulan namun suplai sektor ini berasal dari luar wilayah Kapet Biak selain itu kedua sektor ini mengindikasikan bahwa tingkat ketergantungan daerah terhadap subsidi dana pusat sangat besar oleh karena itu kedua sektor ini tidak dapat dianggap sebagai sektor unggulan, khusus untuk Kabupaten Biak Numfor tidak memiliki sektor unggulan dapat dimaknai bahwa tingkat ketergantungan barang dan jasa di Kabupaten Biak Numfor berasal dari luar wilayah tersebut atau terjadi kebocoran wilayah. Terlihat juga bahwa sektor pertanian unggul di Kabupaten Waropen oleh karena itu perlu adanya komitmen stakeholders dalam menyepakati sektor pertanian sebagai penggerak perekonomian di wilayah Kapet Biak. Merujuk pada gambar 6, mengindikasikan bahwa sektor pertanian akan diprioritaskan di Kabupaten Nabire dan Waropen.

\section{Potensi Sumberdaya Ikan}

Kapet Biak terdiri dari lima kabupaten dan setiap kabupaten memiliki laut yang selama ini telah dikelola, laut juga sebagai batas administrasi antar kabupaten, UndangUndang Nomor 23 Tahun 2014 tentang Pemerintah Daerah mengatur dengan tegas bahwa luas laut yang dapat dikelola oleh setiap provinsi sepanjang 12 mil dan kabupaten sepanjang 4 mil, luas laut Kapet Biak sebesar 46.006,28 $\mathrm{Km}^{2}$, oleh karena itu laut dipandang sebagai sumberdaya bersama (common pool resources) pada kawasan tersebut.

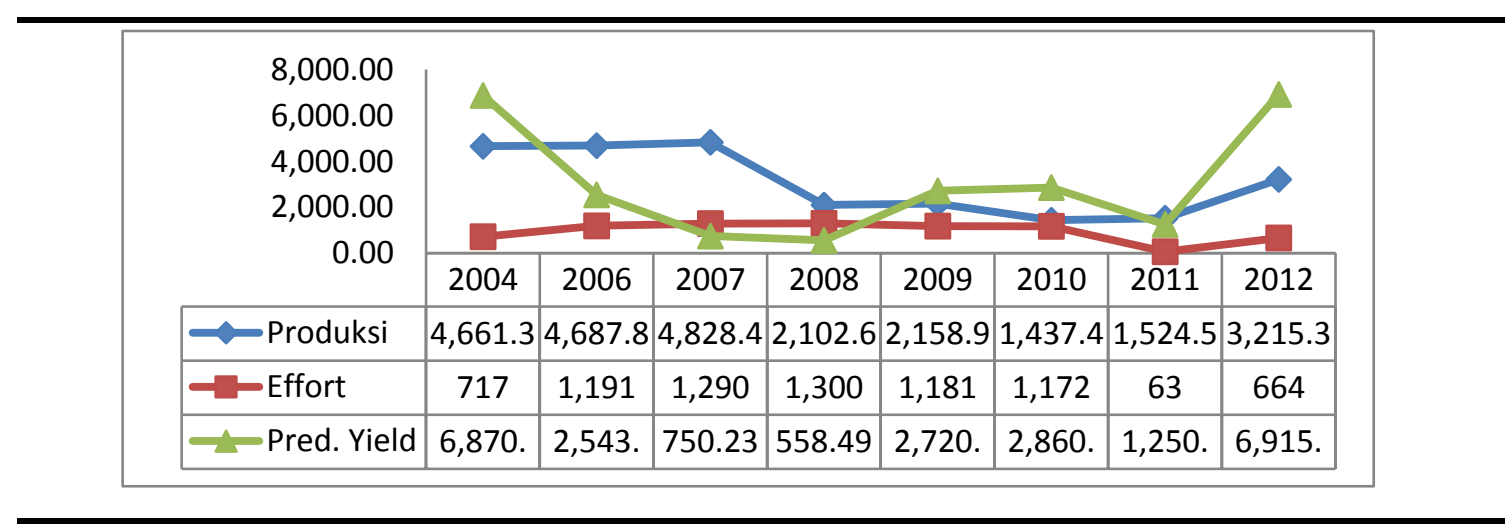

Gambar 6. MSYdi Kabupaten Nabire

Operasional harian menunjukkan bahwa para nelayan selalu menangkap ikan pada musim-musim tertentu tetapi adapula setiap harinya walaupun hasil tangkapan mereka sedikit selain nelayan lokal terdapat nelayan dari luar kawasan dan kapal asing yang melalui perairan tersebut dan menangkap sumberdaya ikan pada laut Kapet Biak. Sebagai 
sumberdaya bersama yang menyimpang berbagai potensi sumberdaya ikan maka perlu untuk diketahui seberapa besar potensi sumber daya ikan di laut Kapet Biak. Hasil estimasi/ perhitungan tangkapan maksimum lestari di setiap kabupaten tertera pada Gambar 6.

Gambar 6 menginformasikan bahwa tangkapan maksimum lestari sebanyak 6.915, ton dengan effort sebesar 664 trip sedangkan produksi yang baru dimanfaatkan oleh para nelayan sebanyak 3.215,30 ton. Begitupula di Kabupaten Kepulauan Yapen, prediksi tangkapan maksimum lestari sebesar 12.025,6 ton sedangkan yang baru dikelola sebesar 3.399,30 ton disajikan pada Gambar 7.

\begin{tabular}{|c|c|c|c|c|c|c|c|c|}
\hline \multirow{2}{*}{$\begin{array}{r}15,000.00 \\
10,000.00 \\
5,000.00\end{array}$} & & & & $=$ & 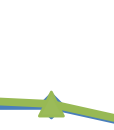 & \multicolumn{2}{|c|}{ 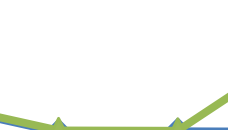 } & \\
\hline & 2004 & 2006 & 2007 & 2008 & 2009 & 2010 & 2011 & 2012 \\
\hline —Produksi & $9,258.6$ & $5,964.5$ & $6,143.2$ & $6,176.7$ & 6,187.1 & 3,350.3 & 3,449.6 & $3,399.3$ \\
\hline- Effort & 1,152 & 1,009 & 977 & 1,075 & 960 & 487 & 482 & 3,041 \\
\hline -Pred. Yield & 7,386 . & 6,654 . & 6,485 . & 6,996. & 6,392 . & 3,544 . & 3,506 . & 12,025 \\
\hline
\end{tabular}

\section{Gambar 7. MSYdi Kabupaten Kepulauan Yapen}

Prediksi tangkapan maksimum lestari di Kabupaten Waropen, tersaji pada Gambar 8 yang menjelaskan bahwa produksi aktual yang dikelola para nelayan sebanyak 2.676,50 ton sedangkan tangkapan maksimum lestari sebesar 3.860,83 ton, sehingga masih tersedia stok sumber daya ikan sebesar $1.184,33$ ton di wilayah perairan laut Waropen.

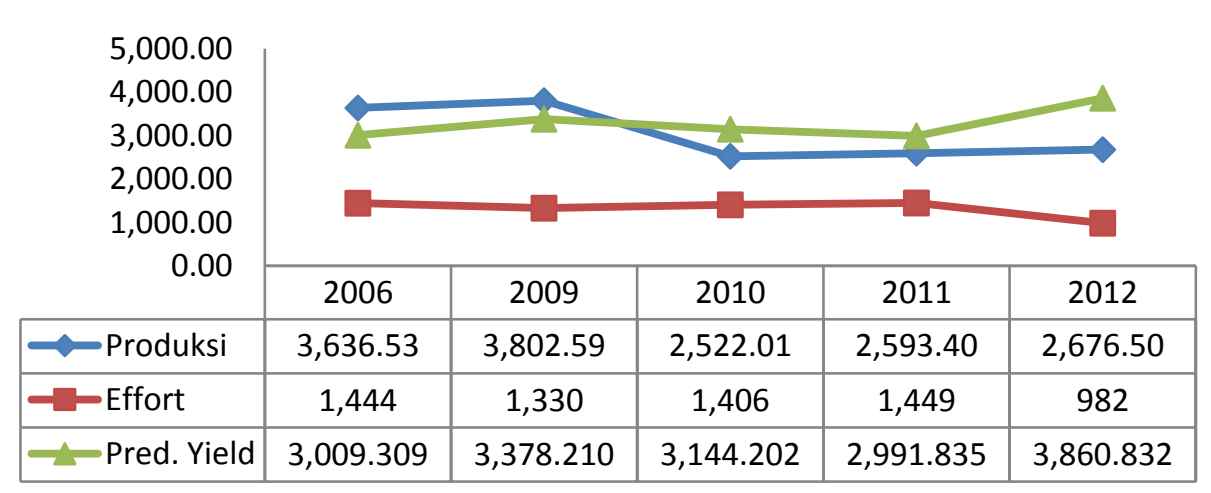

\section{Gambar 8. MSYdi Kabupaten Waropen}

Prediksi tangkapan maksimum lestari di Kabupaten Supiori dan Biak Numfor, masing-masing tersaji pada Gambar 9 dan Gambar 10. Data ini menginformasikan bahwa tangkapan maksimum lestari di perairan laut Supiori sebesar 3.552,359 ton dan yang baru termanfaatkan sebesar 2.510,30 ton, sehingga masih tersedia cadangan sumber daya ikan sebanyak $1.565,636$ ton.

Tangkapan maksimum lestari (MSY) di wilayah Kapet Biak yang berbatasan langsung dengan Samudera Pasifik sehingga mempunyai potensi sumber daya ikan pelagis besar dan pelagis kecil. Ditunjang adanya terumbu karang di perairan Distrik Padaido, 
Biak Timur, Biak, Kota dan Yendidori, sehingga memiliki potensi ikan demersal yang melimpah di lokasi tersebut. Tangkapan maksimum lestari di wilayah perairan Biak Numfor tersaji pada Gambar 10.

\begin{tabular}{|c|c|c|c|c|}
\hline \multirow[t]{2}{*}{$\begin{array}{r}5,000.00 \\
4,000.00 \\
3,000.00 \\
2,000.00 \\
1,000.00 \\
0.00\end{array}$} & & \multirow[b]{2}{*}{2009} & \multirow[b]{2}{*}{2010} & \multirow[b]{2}{*}{2011} \\
\hline & 2006 & & & \\
\hline Produksi & $4,168.50$ & $3,802.60$ & $2,432.10$ & $2,510.30$ \\
\hline -Effort & 2,409 & 2,243 & 2,245 & 1,987 \\
\hline$\sim$ Pred. Yield & $3,391.788$ & $3,493.019$ & $3,492.108$ & $3,552.359$ \\
\hline
\end{tabular}

\section{Gambar 9. MSYdi Kabupaten Supiori}

Interpretasi dari Gambar 10 bahwa produksi aktual yang telah dimanfaatkan para nelayan sebanyak 26.456,63 ton sedangkan prediksi tangkapan maksimum lestari sebanyak 18.921,4 ton. Pemanfaatan sumber daya ikan secara berlebihan (over fishing) akan berdampak terhadap penurunan kuantitas dan kualitas SDi di wilayah perairan laut Biak Numfor. Klasifikasi sumber daya ikan di wilayah perairan kapet Biak disajikan pada Tabel 8.

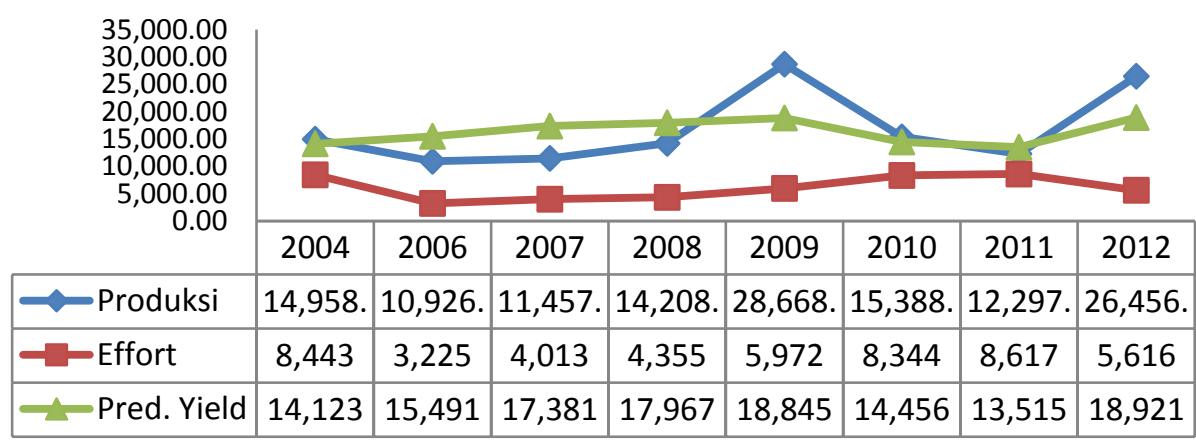

Gambar 10. MSYdi Kabupaten Biak Numfor

Informasi yang disampaikan Tabel 8 menggambarkan bahwa potensi sumberdaya ikan di wilayah Kapet Biak sebesar 45.052 ton/tahun yang terdiri dari pelagis besar 10.294 ton, pelagis kecil 11.962 ton, demersal 14.351 ton, cumi-cumi 2.523 ton, udang 2.924 ton, cucut dan pari sebanyak 3.006 ton. Sumberdaya ikan yang melimpah di wilayah Kapet Biak agar dapat berkelanjutan (sustainable) dikelola dengan pendekatan ekologis oleh masyarakat, pemerintah dan swasta, sehingga ketersediaan biota laut ini terus lestari. Kajian terpadu yang dilakukan oleh KKP, WWF dan PKSPL-IPB menginformasikanbahwa WPP 717 tergolog dalam kategori baik baik (skor 275) (Ditjen Sumber Daya Ikan-KKP, WWF-Indonesia, \& PKSPL-IPB, 2011). Hampir semua indikator habitat menunjukkan kondisi yang sedang sampai baik, kecuali terdapat potensi pencemaran di beberapa wilayah dimana terdapat industry besar. Selain itu tutupan lamun di wilayah ini relative sedang. 
Stakeholders yang dikenal dengan tiga tungku yang terdiri dari pemerintah, agama dan adat harus membuat konsensus bersama guna melestarikan biota laut, maraknya perikanan tangkap menyebabkan aquaculture seolah-olah diabaikan oleh karena itu kawasan yang kawasan yang produksi aktualnya melebihi potensi maksimum lestari dianjukan agar melakukan pendekatan aquaculture, sehingga diharapkan kondisi biologis laut akan pulih selain itu jumlah dan jenis alat tangkap serta armada diatur seminimal mungkin, apabila ada kapal-kapal dari luar kawasan yang menangkap ikan di wilayah Kapet Biak maka perlu adanya retribusi atau pajak sumberdaya ikan sehingga dapat digunakan untuk pengembangan wilayah lebih khusus pelestarian sumberdaya laut.

Tabel 8. Potensi Sumberdaya Ikan di Wilayah Kapet Biak

\begin{tabular}{|c|c|c|c|}
\hline Wilayah Kapet Biak & Klasifikasi Ikan & Jumlah(ton) & Persentase(\%) \\
\hline \multirow[t]{6}{*}{ Nabire } & Pelagis Besar & 1.673 & 25 \\
\hline & Pelagis Kecil & 2.744 & 41 \\
\hline & Demersal & 1.271 & 19 \\
\hline & Cumi-cumi & 335 & 5 \\
\hline & Udang & 201 & 2 \\
\hline & Cucut dan Pari & 468 & 7 \\
\hline \multirow[t]{6}{*}{ Waropen } & Pelagis Besar & 386 & 10 \\
\hline & Pelagis Kecil & 772 & 20 \\
\hline & Demersal & 579 & 15 \\
\hline & Cumi-cumi & 270 & 7 \\
\hline & Udang & 1.776 & 46 \\
\hline & Cucut dan Pari & 77 & 2 \\
\hline \multirow[t]{6}{*}{ Kepulauan Yapen } & Pelagis Besar & 2.044 & 17 \\
\hline & Pelagis Kecil & 3.968 & 33 \\
\hline & Demersal & 4.329 & 36 \\
\hline & Cumi-cumi & 842 & 7 \\
\hline & Udang & 361 & 3 \\
\hline & Cucut dan Pari & 481 & 4 \\
\hline \multirow[t]{5}{*}{ Supiori } & Pelagis Besar & 514 & 14 \\
\hline & Pelagis Kecil & 694 & 20 \\
\hline & Demersal & 1.360 & 38 \\
\hline & Cumi-cumi & 310 & 9 \\
\hline & Udang & 208 & 6 \\
\hline \multirow[t]{7}{*}{ Biak Numfor } & Cucut dan Pari & 466 & 13 \\
\hline & Pelagis Besar & 5.676 & 30 \\
\hline & Pelagis Kecil & 3.784 & 20 \\
\hline & Demersal & 6.812 & 36 \\
\hline & Cumi-cumi & 757 & 4 \\
\hline & Udang & 378 & 2 \\
\hline & Cucut dan Pari & 1.514 & 8 \\
\hline
\end{tabular}

Sumber : BPS Provinsi Papua (data diolah)

\section{Kesimpulan}

Hasil dan pembahasan memberikan beberapa simpulan sebagai berikut Pendekatan pertumbuhan ekonomi dan pendapatan per kapita mengindikasikan bahwa Kapet Biak tergolong sebagai wilayah yang belum berkembang tetapi aspek IPM dan pertumbuhan ekonomi mendeskripsikan bahwa kawasan ini merupakan wilayah yang cepat maju dan cepat tumbuh. Pertumbuhan dan perkembangan kawasan ini dipengaruhi oleh kontribusi sektor jasa sedangkan sektor primer yang menjadi prime mover perekonomian kurang memilki kontribusi yang besar. Setiap wilayah Kapet Biak memiliki karakteristik sektor 
yang dapat menopang wilayahnya masing-masing, hanya Kabupaten Waropen dan Supiori yang memiliki sektor unggulan sedangkan Kabupaten Nabire, Kepulauan Yapen dan Biak Numfor memiliki sektor basis dan komparatif yanf dapat menopang dan memberikan kontribusi terhadap pertumbuhan wilayah dan pendapat per kapita di wilayah tersebut. Laut sebagai sumberdaya bersama dan penyatu antar Kapet Biak memiliki potensi sumberdaya ikan pelagis besar, pelagis kecil, demersal, udang, cumi, cucut dan pari yang potensi lestarinya fluktuatif sehingga dapat dikelola oleh semua pihak untuk meningkatkan pendapatan per kapita dan pertumbuhan wilayah dengan pendekatan ekologis (sustainable), jumlah catch, effort, armada dan melakukan upaya aquaculture serta diversifikasi produk pengolahan perikanan.

\section{Daftar Pustaka}

Badan Pusat Statistik Kabupaten Nabire. (2013). Nabire Dalam Angka.

Badan Pusat Statistik Provinsi Papua. (2013). Papua Dalam Angka. Jayapura.

Bing, L. (2011). The Study of Labor Mobility and Its Impact on Regional Economic Growth. Procedia Environmental Sciences, 10, 922-928.

Ditjen Sumber Daya Ikan-KKP, WWF-Indonesia, \& PKSPL-IPB. (2011). Kajian Awal Keragaan Pendekatan Ekosistem Dalam Pengelolaan Perikanan (Ecosystem Approach to Fisheries Management) di Wilayah Pengelolaan Perikanan Indonesia.

Hardjowigeno, S., \& Widiatmaka. (2011). Evaluasi Kesesuaian Lahan \& Perencanaan Tata Guna Lahan. Yogyakarta: Gadjah Mada University Press.

Kuncoro, M. (2004). Otonomi dan Pembangunan Daerah: Reformasi, Perencanaan, Strategi dan Peluang. Jakarta: Penerbit Erlangga.

Rustiadi, E., Saefulhakim, S., \& Panuju, D. (2011). Perencanaan dan Pengembangan Wilayah. Jakarta: Crespent dan Yayasan Pustaka Obor Indonesia Press. 